\title{
TREATMENT OF SUBCLAVIAN STEAL SYNDROME WITH PERCUTANEOUS TRANSLUMINAL ANGIOPLASTY AND STENTING
}

\section{Case report}

\author{
Felipe Fregni', Luiz Eduardo Coutinho Castelo-Branco', Adriana Bastos Conforto², \\ Fabio luji Yamamoto², Cynthia Resende Campos ${ }^{3}$, Paulo Puglia Jr.4, \\ José Guilherme Mendes Pereira Caldas ${ }^{5}$, Milberto Scaff6.
}

\begin{abstract}
Subclavian steal syndrome refers to the association of neurological symptoms related to vertebrobasilar insufficiency and the phenomenon of subclavian steal. We report the case of a 63 year-old male patient that presented subclavian steal syndrome and severe proximal $(80 \%)$ stenosis of the left subclavian artery. The patient was submitted to percutaneous transluminal angioplasty and stenting on the left SA. The procedure was well tolerated and immediately afterwards, there was complete remission of the symptoms and of the phenomenon of subclavian steal evaluated by angiography and transcranial doppler. We propose that percutaneous transluminal angioplasty with stenting placement is a good therapeutic option for subclavian steal syndrome.
\end{abstract}

KEY WORDS: subclavian steal syndrome, subclavian artery stenosis, peripheral arterial stents, stents in brachiocephalic arteries, primary stent deployment.

\section{Tratamento de síndrome de roubo de subclávia com angioplastia transluminal percutânea e stenting: relato de caso}

RESUMO - A síndrome do roubo de subclávia designa a associação de sintomas neurológicos de insuficiência vertebrobasilar ao fenômeno do roubo de subclávia. Relatamos o caso de um homem de 63 anos que apresentava a síndrome do roubo de subclávia e estenose proximal grave (80\%) da artéria subclávia esquerda (ASE). O paciente foi submetido a angioplastia transluminal percutânea com colocação de "stent" na ASE. O procedimento foi bem tolerado e, imediatamente após, houve remissão dos sintomas e do fenômeno de roubo de subclávia, avaliado por angiografia e doppler transcraniano. Propomos que a angioplastia transluminal percutânea com a colocação de "stent" é uma boa opção terapêutica para a síndrome de roubo de subclávia.

PALAVRAS-CHAVE: síndrome de roubo de subclávia, estenose de artéria subclávia, "stents" em artérias periféricas, "stents" em artérias braquiocefálicas, colocação primária de "stents".

The phenomenon of subclavian steal is caused by occlusion or stenosis of the proximal subclavian artery (SA) with subsequent retrograde filling of the SA via the ipsilateral vertebral artery (VA) ${ }^{1,2}$. The designation "subclavian steal" was coined by Miller Fischer in 1961 to characterize 2 cases reported by Reivich et al. ${ }^{3}$. One of the patients had presented attacks of recurrent throbbing pain in the left mastoid area precipitated by exercise and 4 episodes of left arm paralysis lasting for 15 minutes. The other patient had had episodes of visual blurring lasting for about 5 minutes. In both cases, arteriograms disclosed severe left SA stenosis, proximal to the origin of the VA. Therefore, blood flow went up to the right VA, down to the left VA and into the left SA to supply the arteries on the left arm. In the same article, Reivich et al. ${ }^{3}$ confirmed the haemodynamic phenomenon in 4 dogs. In these animals, the SAs were compressed proximally to produce arterial stenosis ${ }^{3}$.

\footnotetext{
${ }^{1}$ Resident, Neurology Division, Hospital das Clínicas, São Paulo University, São Paulo SP, Brazil (HC/FMUSP); ${ }^{2}$ Staff Physician, Neurology Division, HC/FMUSP; ${ }^{3}$ Chief Resident, Neurology Division, HC/FMUSP; ${ }^{4}$ Staff Physician, Interventional Neuroradiology, Radiology Institute, HC/FMUSP; ${ }^{5}$ Chief, Interventional Neuroradiology, Radiology Institute, HC/FMUSP; ${ }^{6}$ Chairman, Neurology Division, HC/FMUSP.
}

Received 22 July 2002, received in final form 12 September 2002. Accepted 18 September 2002. 
Subclavian steal syndrome (SSS) is not a synonym for SA stenosis. SA occlusive disease may be clinically silent, especially when the amount of blood supply of the ipsilateral VA is compensated by the contralateral VA or from the carotid system through the circle of Willis. Obstruction involves the left SA more frequently than the right, and associated arterial lesions are found in more than $80 \%$ of the cases ${ }^{4}$. When compensation does not occur, patients may present symptoms related to vertebrobasilar insufficiency: light-headedness, dizziness, vertigo, ataxia, visual disturbances, motor deficits, focal seizures, and confusion'. Symptoms may develop during exercise of the upper limbs, when blood is deviated from the vertebrobasilar system to the upper limb. SA stenosis may also present with upper-extremity claudication and fatigue or even angina pectoris as a result of coronary artery steal with retrograde blood flow occurring after upper-extremity exercise ${ }^{5}$. Common findings in SA stenosis are: bruits over the SA, decrease of blood pressure and intermittent claudication of the arm ipsilateral to the affected $\mathrm{SA}^{6}$. Subclavian steal can be demonstrated by transcranial doppler (TCD) with the subclavian-steal test. The VA is insonated with the patient at rest with a bloodpressure cuff applied to the arm ipsilateral to the SA stenosis. The cuff is inflated above systolic pressure for $3 \mathrm{~min}$. The patient exercises the arm during the last $30 \mathrm{~s}$ of occlusion, and the cuff is quickly deflated. The test is positive if complete reversal of vertebral flow occurs when the cuff is deflated. If the flow is bidirectional on removal of the cuff but normal at rest the phenomenon is termed "pre-steal" 7 .
Therapeutic options for SA stenosis have involved surgical procedures such as transthoracic and extrathoracic revascularization. Although these procedures have been effective, associated morbidity and mortality (5-19\%) have limited their use ${ }^{5,8}$. Complications are mainly related to coexistent coronary and cerebrovascular disease. Intrathoracic surgical approaches, in particular, may have complications such as thrombosis, chylothorax, and Horner syndrome ${ }^{9}$. Percutaneous transluminal angioplasty (PTA) was first used for the treatment of this condition in $1980^{4}$, however this procedure may have complications such as restenosis, thrombosis and stroke. Millaire and colleague ${ }^{10}$ described $10 \%$ of complications using PTA for subclavian stenosis. They found $14 \%$ of restenosis after a follow-up of 39 months in average. PTA followed by stenting results in technical improvements: prevention of intimal tear and abrupt vessel closure, as well as trapping of embolic debris formed during the procedure and less delayed restenosis ${ }^{11}$.

We report successful treatment of subclavian steal syndrome by PTA and stenting of the left SA.

\section{CASE}

A 63 year-old man, with a past medical history of arterial hypertension, tobacco and alcohol use, presented several transient attacks of tinnitus in the right ear, dizziness and bilateral blindness lasting for approximately 20 seconds. He reported having around four episodes per month, mainly while in upright position. He also complained of pain and numbness on the left arm after exercising the upper limbs. At the age of 62 , he had had an episode of weakness, tingling and numbness on left upper and lower limbs, with complete remission after 2 days. He also

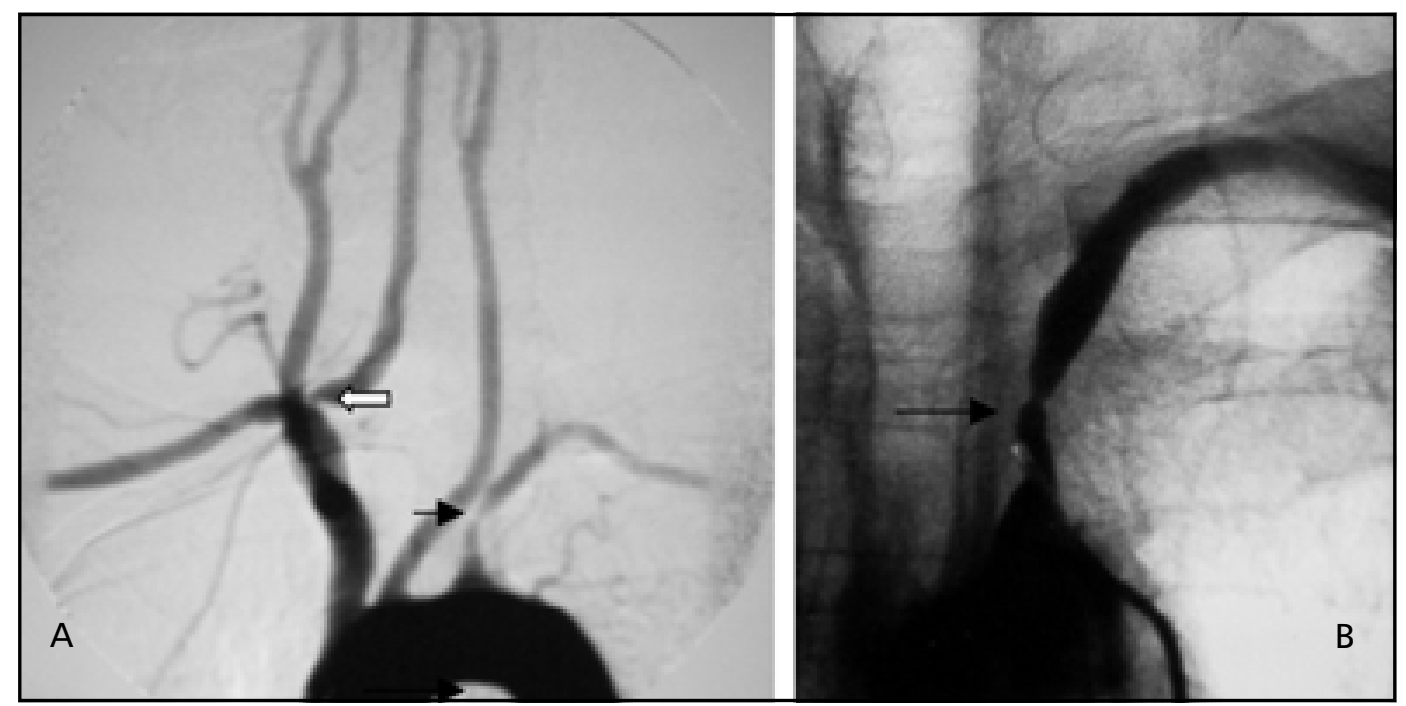

Fig 1. Angiography showed severe stenosis (80\%) of the proximal left SA (black arrow) and mild stenosis (40\%) at the origin of the right VA (white arrow). 


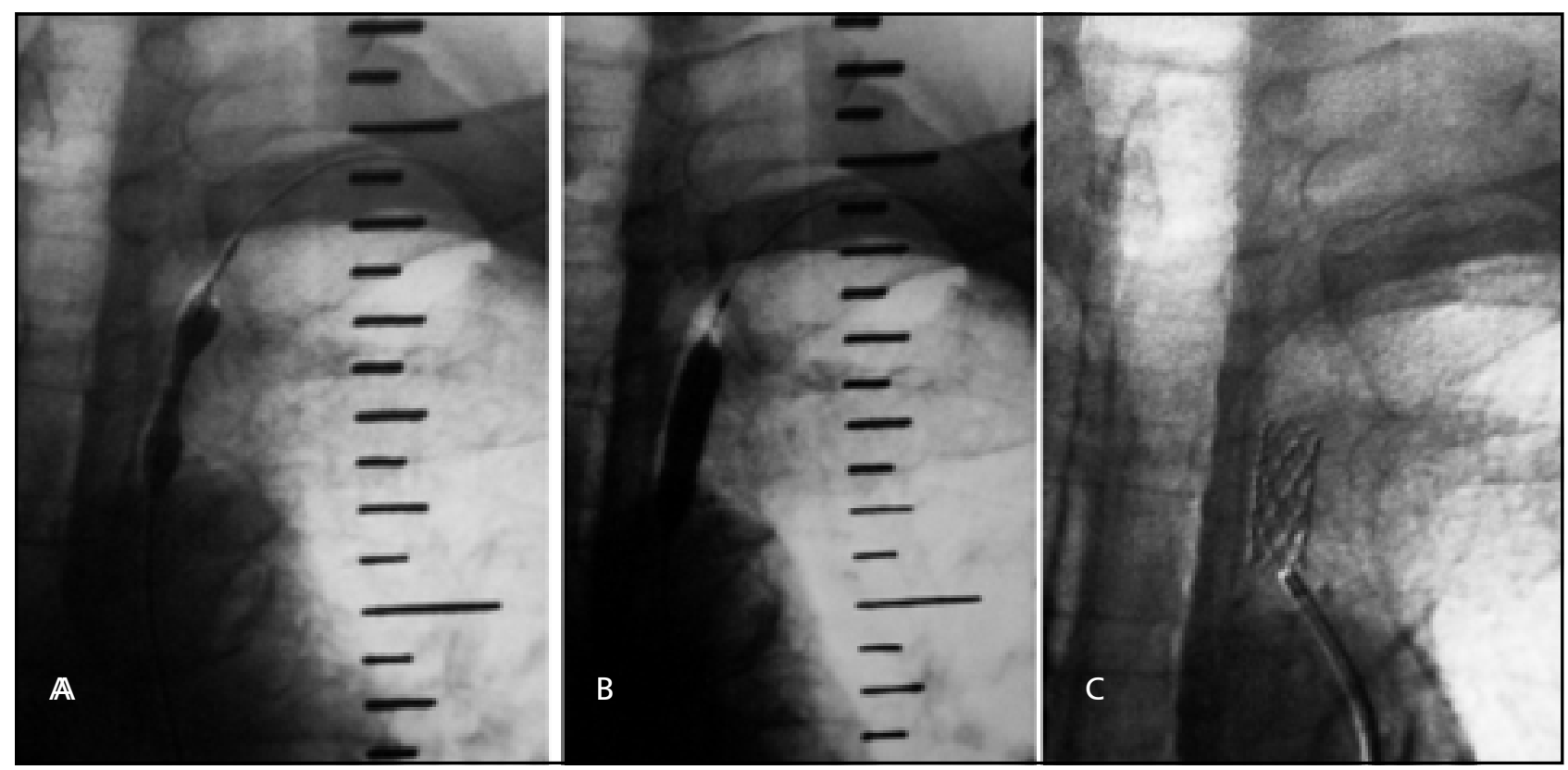

Fig 2. Balloon during PTA. A - Dilatation of left SA. B - Full dilatation of the left SA. C - Stent deployment.

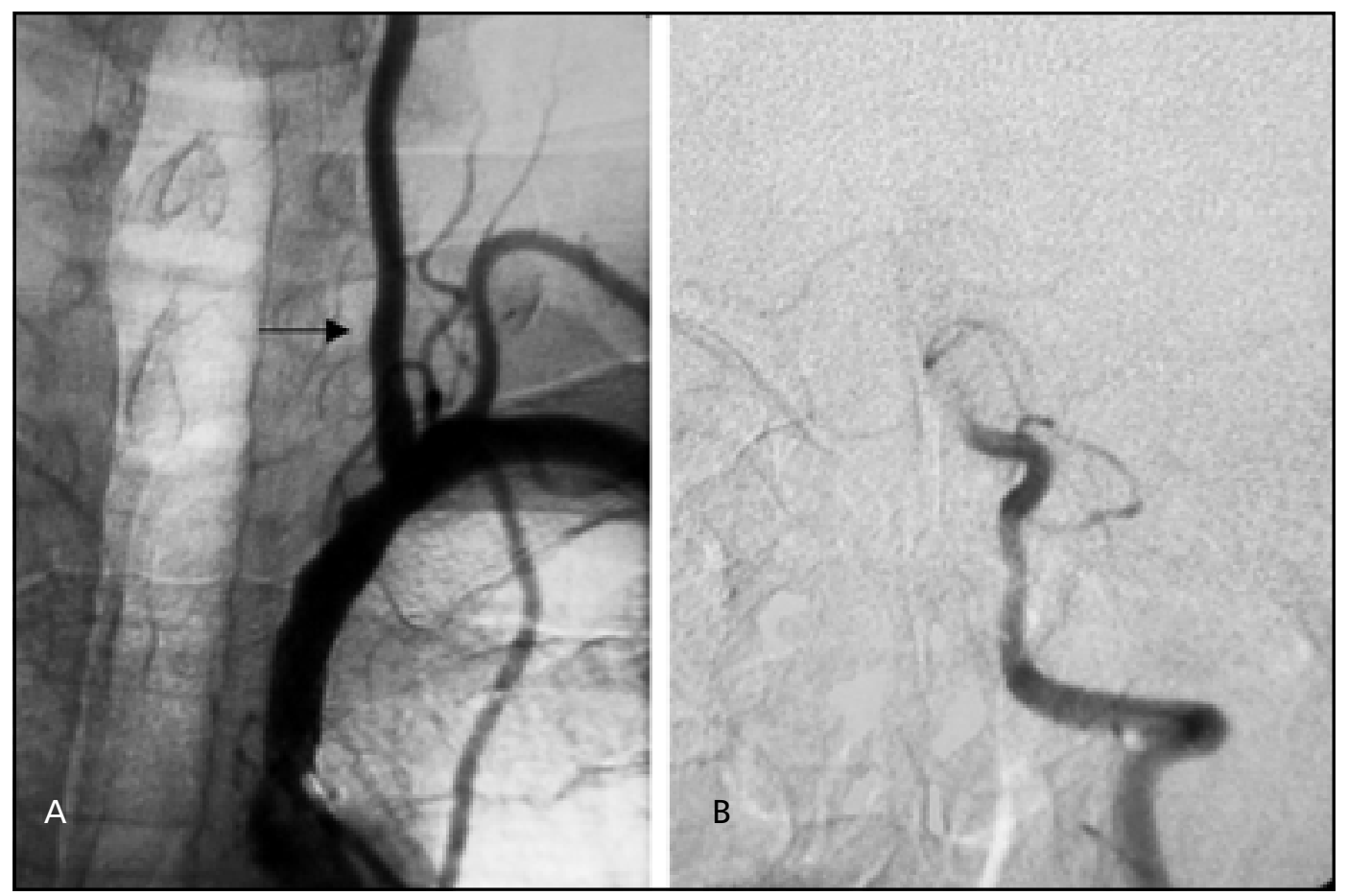

Fig 3. Angiography after PTA and stenting on the left SA. A - Anterograde flow in left vertebral artery (arrow). $B$ - Flow in the left verterbal artery after PTA.

had had two previous episodes of arterial thrombosis, one on the left lower limb at the age of 43 and one on the right upper limb at the age of 48 . In both occasions he had been submitted to thrombectomy. He had also undergone mitral valvoplasty at the age of 46 due to rheumatic valvopathy. At the age of 56, he had had an acute ischemic stroke presenting with right hemiparesis. A few days later, he had a myocardial infarct, and was submitted to coronary angioplasty. Since then, the patient had been using captopril $25 \mathrm{mg}$ tid, furosemide $40 \mathrm{mg}$ qd and aspirin $100 \mathrm{mg}$ qd.

The physical exam revealed an irregular pulse, $82 / \mathrm{min}$ (the left radial pulse was diminished). Blood pressure was $140 / 90 \mathrm{mmHg}$ on the right arm and $80 / 50 \mathrm{mmHg}$ on the left. Cardiac examination disclosed an irregular rhythm and a grade III-IV/VI middiastolic murmur at the left sternal border was observed. No carotid bruits were heard. The 
patient had a subtle right hemiparesis. Tendon reflexes were brisker on the right side. The neurologic exam was otherwise normal. The electrocardiogram showed atrial fibrillation and the chest radiography revealed cardiomegaly. Noncontrast head computed tomography showed a small infarct in the left corona radiata that was confirmed by magnetic resonance imaging. An enlarged left atrium $(64 \mathrm{~mm})$ with a mural thrombus, as well as mitral stenosis and insufficiency were observed in a transesophageal echocardiogram. TCD disclosed decreased velocities in both carotid, vertebral and basilar arteries, and inversion of flow in the left vertebral artery after exercising the left arm (subclavian steal test). Angiography (Fig 1) showed severe stenosis $(80 \%)$ of the left SA (proximal) and mild stenosis $(40 \%)$ at the origin of the right VA. The subclavian steal phenomenon was present in the left SA.

The patient was submitted to PTA and stenting on the left SA (Fig 2). Vascular access (femoral) was obtained by cannulating the artery percutaneously using the Seldinger technique. A 6 French sheath was introduced, and 7500 units of heparin were administered. An angiographic catheter was advanced over a guidewire to the site of the lesion. Stenotic lesions were crossed using a steerable 0.0014 -inch extrasupport $260 \mathrm{~cm}$ long guidewire. The angiographic catheter was then changed, over the exchange guidewire to a balloon expandable Palmaz-Corinthian stent that was placed over the lesion. The stent was deployed using fluoroscopic roadmapping guidance. Balloon was deflated and angiography was obtained to assure the positioning and result (Fig 3). Only then, the guidewire was removed, followed by sheat removal. The procedure was well tolerated and immediately afterwards, there was complete remission of the left arm pain and numbness during exercise. TCD after the procedure no longer showed inversion of flow in the left vertebral artery. The patient was put on heparin that was substituted by warfarin to prevent cardiogenic embolism associated with atrial fibrillation and mitral valvopathy.

\section{DISCUSSION}

Pain, numbness, or fatigue in the arm have been reported in about one third of patients with SA stenosis. Only $5 \%$ of the patients have cyanosis and trophic skin changes due to severe brachial ischemia or embolism in distal arterial branches of the upper limbs. Approximately $77 \%$ of the patients show a systolic pressure differential greater than $20 \mathrm{mmHg}$ and in $85 \%$, radial pulses are diminished in the involved $\mathrm{arms}^{2}$. Our patient presented all of the above symptoms. He also had neurologic symptoms characteristically associated with the vertebrobasilar system: dizziness, tinnitus and bilateral blindness. Some authors have claimed that cerebrovascular symptoms in patients that present SA stenosis may not be caused by the subclavian steal phenomenon. Bornstein and Norris ${ }^{12}$ followed 500 patients with asymptomatic neck bruits. Thirty two patients had positive subclavian steal tests and 8 patients had positive presteal tests. However, none of these patients had symptoms after exercising the arm during the test, nor had strokes during a 4-year follow up. It was concluded that reversal of flow in the VA might be a harmless haemodynamic phenomenon.

Hennerici and colleagues ${ }^{4}$ reported hemispheric neurological events in $3 \%$ of 324 patients, that had been found to present reversed VA flow by TCD. These patients did not have symptoms of subclavian steal syndrome. In $5 \%$ of the cases, the symptoms were nonhemispheric. They concluded that this condition was benign and was seldom associated with neurologic deficits. Subclavian steal, in their view, would be a marker for coexisting severe atherosclerotic extracranial, coronary artery and peripheral vascular occlusive disease. Neurologic events that might occur would be related to this diffuse atherosclerotic disease ${ }^{2}$.Other authors have argued that $80 \%$ of the patients that present subclavian steal also have extracranial internal carotid obstruction and that this obstruction might be the main cause of the symptoms. Our patient, on the contrary, did not have any carotid obstruction as confirmed by angiography. There are still some doubts about the best management for the angiographic phenomenon of subclavian steal. However, when the phenomenon is associated with clinical manifestations such as dizziness, vertigo, ataxia, visual disturbances, motor deficits, focal seizures, confusion or syncope, some authors have recommended treatment for the symptomatic SA with PTA and/ or stenting ${ }^{1,5,13}$.

Erbstein et al. ${ }^{9}$ reported a rate of success of $88 \%$ in 24 patients treated with PTA of the proximal SA. 17 of the patients had had symptoms of subclavian steal syndrome. Symptoms recurred in 3 of the patients, and one patient suffered brachial artery occlusion after the procedure. Bachman and $\mathrm{Kim}^{14}$ described a successful outcome using PTA for the treatment of SSS. They reported a patient with SSS that received PTA followed by heparin (1000 U/hr) with continuous intravenous infusion for $48 \mathrm{hr}$ after the procedure. Eleven months later, the patients had remained asymptomatic. Motarjeme et al. ${ }^{15}$, in a review about PTA of the supra-aortic vessels, studied 112 patients that were submitted to treatment of 151 lesions in the innominate, subclavian, carotid, and vertebral arteries. 141 (93\%) of 151 lesions were successfully treated. PTA achieved a rate of success of $100 \%$ in SA stenosis $(n=67)$. In 13 cases of SA occlu- 
sion, however, only $6(46 \%)$ recanalized. There were 3 periprocedural complications, but only 1 was major: a focal stroke presenting as right arm weakness occurred in a patient with left common carotid PTA and stenting. 5 cases of reocclusion have been diagnosed in 5 years of follow-up, and 3 of the 5 were in arteries originally occluded. He concluded that PTA can achieve excellent immediate and long-term results in proximal SA stenosis, however SA occlusions may not respond well to PTA, and those successfully recanalized have a high reocclusion rate $(50 \%)$.

Stenting has been considered safe. Risks related to this procedure are stroke, arterial rupture, and reocclusion. Kumar and colleagues ${ }^{5}$ studied a series of 27 patients treated with stenting for SA stenosis. The indications for intervention were SSS in 11 patients, arm claudication in 8 patients, angina pectoris following internal mammary coronary artery revascularization surgery in 6 patients, and recanalization of an occluded left SA to facilitate another intervention procedure in 2 patients. Complications occurred in only 2 patients: stent dislodgment with migration into external iliac artery in one case, and formation of a hematoma with need of surgical repair in another ${ }^{5}$. Sueoka ${ }^{16}$ performed stenting in 7 patients with stenosis or occlusion of the left SA that presented vertigo, syncope or left arm claudication. There were no complications, and all of the patients had complete remissions in a clinical follow-up of 1 year. Sakaida et al. ${ }^{17}$ achieved a $75 \%$ success rate in $7 \mathrm{ca}-$ ses of stenting (5 left SA, 2 right SA and 1 braquiocephalic trunk). Artery dissection occurred in 2 cases, stenting dislodgment and migration in 1 case. None of these patients had strokes. Martinez et al. ${ }^{18}$ reported the results of stenting in 17 patients who underwent treatment for total occlusions in the SAs. As complications, they had 2 cases of stent migration during deployment, resulting in a $94 \%$ procedural success rate. There were no postprocedural neurologic complications or deaths. Follow-up over a mean duration of 19,4 months revealed 1 asymptomatic restenosis at 5 months in a patient with 3 stents.

Considering that this patient carried a high risk profile for surgical procedures, as he had had a myocardial infarct followed by atrial fibrillation, PTA and stenting were considered the best options. Low complications may be achieved with this technique $\mathrm{e}^{7,19,20}$.

This report, as well as the literature suggest that PTA and stenting can be a good option for symptomatic subclavian steal syndrome associated with subclavian stenosis. Randomized clinical trials will further elucidate the benefits of this therapeutic approach in the future.

\section{REFERENCES}

1. Chan-Tack KM. Subclavian steal syndrome: a rare but important cause of syncope. South Med J 2001;94:445-447.

2. Hennerici M, Klemm C, Rautenberg W. The subclavian steal phenomenon: a common vascular disorder with rare neurologic deficits. Neurology 1988;38:669-673

3. Reivich M, Holling HE, Roberts B, Toole JF. Reversal of blood flow through the vertebral artery and its effect on cerebral circulation. N Engl J Med 1961;265:878-885.

4. Fields WS, Lemak NA. Joint study of extracranial arterial occlusion VII. Subclavian steal - a review of 168 cases. JAMA 1972;222:1139-1143.

5. Kumar K, Dorros G, Bates MC, Palmer L, Mathiak L, Dufek C. Primary stent deployment in occlusive subclavian artery disease. Cathet Cardiovasc Diagn 1995;34:281-285.

6. Fischer CA. Subclavian steal syndrome. Editorial. N Engl J Med 1961;265:912-913.

7. Branchereau A, Magnan PE, Espinoza, H, Bartoli JM. Subclavian artery stenosis: hemodynamic aspects and surgical outcome. J Cardiovasc Surg (Torino). 1991;32:604-612.

8. Eisenhauer AC. Subclavian and innominate revascularization: surgical therapy versus catheter-based intervention. Curr Interv Cardiol Rep 2000;2:101-110.

9. Ersbstein RA, Wholey MH, Smoot S. Subclavian artery steal syndrome: treatment by percutaneuos transluminal angioplasty. AJR 1988;151:291-294.

10. Millaire A, Trinca M, Marache P, de Groote P, Jabinet JL, Ducloux G. Subclavian angioplasty: immediate and late results in 50 patients. Cathet Cardiovasc Diagn 1993;29:8-17.

11. Mathias KD, Lüth I, Haarmann P. Percutaneous transluminal angioplasty of proximal subclavian artery occlusions. Cardiovasc Intervent Radiol 1993;16:214-218.

12. Bornstein NM, Norris JW. Subclavian steal: a harmless haemodynamic phenomen? Lancet 1986;2:303-305.

13. Giavroglou C, Proios T, Daponte P, Loannidis I, Paraskevaidis S, Louridas G. Coronary-subclavian steal syndrome: treatment with percutaneous transluminal angioplasty and stent placement. Eur Radiol 1999;9:948-950.

14. Bachamn DM, Kim RM Transluminal dilatation for subclavian steal syndrome. AJR 1980;135:995-996.

15. Motarjeme A. Percutaneous transluminal angioplasty of supra-aortic vessels. J Endovasc Surg 1996;3:171-181.

16. Sueoka BL. Percutaneous transluminal stent placement to treat subclavian steal syndrome. J Vasc Interv Radiol 1996;7:351-356.

17. Sakaida H, Sakai N, Nagata I et al. Stenting for proximal subclavian and brachiocephalic artery occlusion - preliminary results. No Shinkei Geka 2001;29:717-725.

18. Martinez R, Rodriguez-Lopez J, Torruella L, Ray L, Lopez-Galarza L, Diethrich EB. Stenting for occlusion of the subclavian arteries. Technical aspects and follow-up results. Tex Heart Inst J 1997;24:23-27.

19. Kerr AJ, Williams MJ, Wilkins GT. Primary stenting as treatment for coronary-subclavian steal syndrome. Aust N Z J Med 1997;27:80-81.

20. Jaeger HJ, Mathias KD, Kempkes U. Bilateral subclavian steal syndrome: treatment with percutaneous transluminal angioplasty and stent placement. Cardiovasc Intervent Radiol 1994;17:328-332. 